\title{
Cistitis y pielitis enfisematosas: otra complicación en el paciente diabético
}

\author{
Alicia Panadero Sánchez a , Pablo Franquelo Morales ${ }^{a}$, Gregorio Garde Barea ${ }^{a}$, \\ Susana Losada Ruiza.
}

aServicio de Urgencias. Hospital Virgen de la Luz. Cuenca. España.

Correspondencia: Pablo

Franquelo Morales,

Servicio de Urgencias,

Hospital Virgen de la Luz,

Hermandad de Donantes de

Sangre $n^{\circ} 2,16002$.Cuenca.

España,

Correo electrónico:

pfranquelo@yahoo.es

Recibido el 23 de febrero de 2012.

Aceptado para su publicación el 30 de marzo de 2012

\section{RESUMEN}

La cistitis enfisematosa es una complicación poco frecuente que suele estar asociada a diferentes factores de riesgo, fundamentalmente a la Diabetes Mellitus. Presenta clínica inespecífica de irritación vesical y dolor abdominal revelándose habitualmente como un hallazgo radiológico. La tomografía computarizada abdominal es la prueba diagnóstica de elección. El tratamiento requiere estricto control glucémico, antibioterapia intensiva y drenaje urinario de forma precoz con lo que se resuelven la mayoría de los casos. Puede complicarse afectando a cualquier parte del sistema urinario lo que empeora el pronóstico.

Palabras clave. Cistitis enfisematosa, Diabetes mellitus.

\section{ABSTRACT}

Emphysematous cystitis and pyelitis: another complication in diabetic patients

Emphysematous cystitis is a rare complication that is often associated with different risk factors mainly diabetes mellitus. Presents nonspecific clinical bladder irritation and abdominal pain usually revealed as a radiological finding. Abdominal computed tomography is the method of choice for diagnosis. Treatment requires strict glycemic control, early and intensive antibiotic therapy and urinary drainage that solve most cases. It can be complicated to affect any part of the urinary system which worsens the prognosis.

Key words. Emphysematous cystitis, Diabetes mellitus.

\section{INTRODUCCIÓN}

La diabetes mellitus (DM) constituye un importante problema de salud pública con una tendencia creciente en los últimos años. Representa además una de las principales causas de muerte en los países desarrollados, con múltiples complicaciones macro y microvasculares, que afectan fundamentalmente al sistema cardiovascular, renal y retina ${ }^{1}$. El progresivo envejecimiento de la población y la adopción de estilos de vida poco saludables la convierten hoy día en una patología muy común en nuestras consultas. En este sentido, resulta fundamental por parte del médico de atención primaria, una adecuada intervención sobre los factores de riesgo así como un abordaje precoz de sus potenciales complicaciones. Presentamos un paciente diabético de larga evolución que sufrió una complicación poco frecuente por afectación del sistema urológico con una imagen radiológica reveladora y con consecuencias fatales si no se hubiera identificado a tiempo.

\section{OBSERVACIONES CLÍNICAS}

Varón de 73 años que consultó por deterioro del estado general de unos 10 días de evolución, con anorexia, astenia, sensación distérmica y vómitos esporádicos. No refería dolor abdominal ni síntomas de irritación vesical.

Entre sus antecedentes destacaba una DM tipo 2 con insuficiencia renal crónica, y una hipertrofia benigna de próstata por lo que era portador de sonda vesical. En la exploración física se mostraba afebril con una tensión arterial de 127/72 mmHg. Tan sólo destacaba la presencia de una hernia inguinal 
bilateral de gran tamaño y tiempo de evolución que no le ocasionaba molestias, así como un leve dolor a la puñopercusión renal bilateral.

Las pruebas analíticas revelaron alteraciones en el hemograma, con una hemoglobina de $11.8 \mathrm{~g} /$ $\mathrm{dL}$, hematíes $4.07 \mathrm{mill} / \mathrm{mmc}$, hematocrito $35 \%$, plaquetas $455000 \mathrm{mil} / \mathrm{mmc}$, leucocitos $11.2 \mathrm{mil} /$ mmc, con $89.7 \%$ de neutrófilos y fibrinógeno 738 $\mathrm{mg} / \mathrm{dL}$. La bioquímica también mostró parámetros alterados como glucosa 749 mg/dL, urea 172 mg/
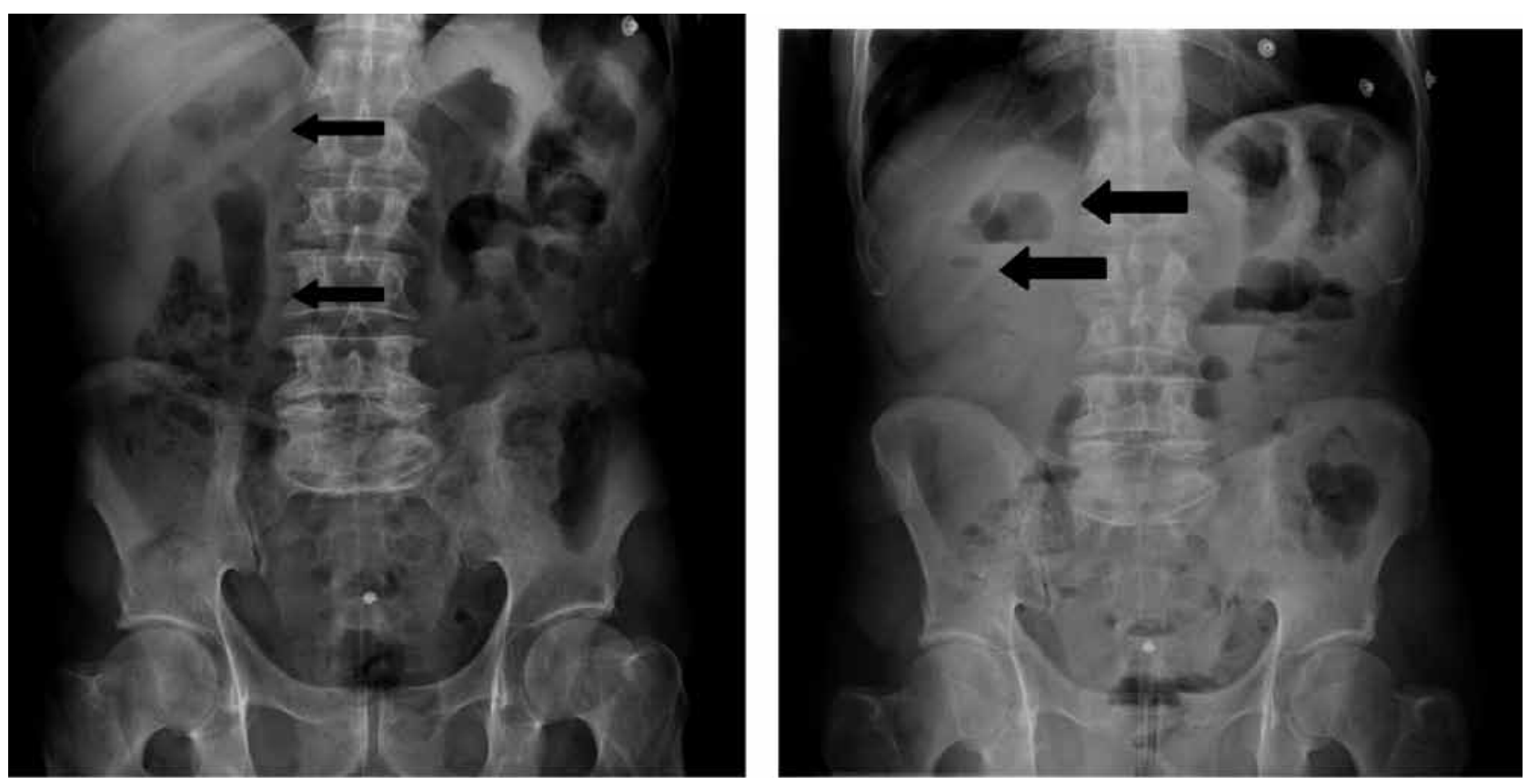

$\mathrm{dL}$, creatinina $4.01 \mathrm{mg} / \mathrm{dL}$, Na $127 \mathrm{mEq} / \mathrm{L}, \mathrm{K} 6.1$ $\mathrm{mEq} / \mathrm{Ly}$ PCR $176 \mathrm{mg} / \mathrm{dL}$. Gasometría venosa con $\mathrm{pH} 7,28$ y $\mathrm{COH} 317.4 \mathrm{mmol} / \mathrm{L}$. Análisis de orina con $1000 \mathrm{mg} / \mathrm{dL}$ de glucosa, hemoglobina 250/ uL, cetonuria y $500 / u L$ leucocitos, con presencia de piuria y hematuria intensas en el sedimento. La radiografía de tórax no mostró hallazgos relevantes, pero en la radiografía simple de abdomen se detectó la presencia de gas en uréter, pelvis y cálices renales derechos, junto a niveles hidroaéreos (figuras 1 y 2).

Figuras 1 y 2.Radiografía PA de abdomen con presencia de gas en sistema pieloureteral derecho sin identificar en izquierdo por gas intestinal.Sonda vesical.

El paciente fue ingresado por infección urinaria complicada y acidosis metabólica en el contexto de una cetoacidosis diabética (CAD). Se administraron sueroterapia, insulina, bicarbonato y antibioterapia de forma precoz con obtención de un urocultivo previo. El informe de la tomografía computerizada (TC) abdomino-pélvica realizada, reveló una dilatación severa de ambas vías excretoras que se encontraban ocupadas por material denso y gas, contorneando los uréteres, pelvis y grupos caliciales. La vejiga presentaba hallazgos similares, 

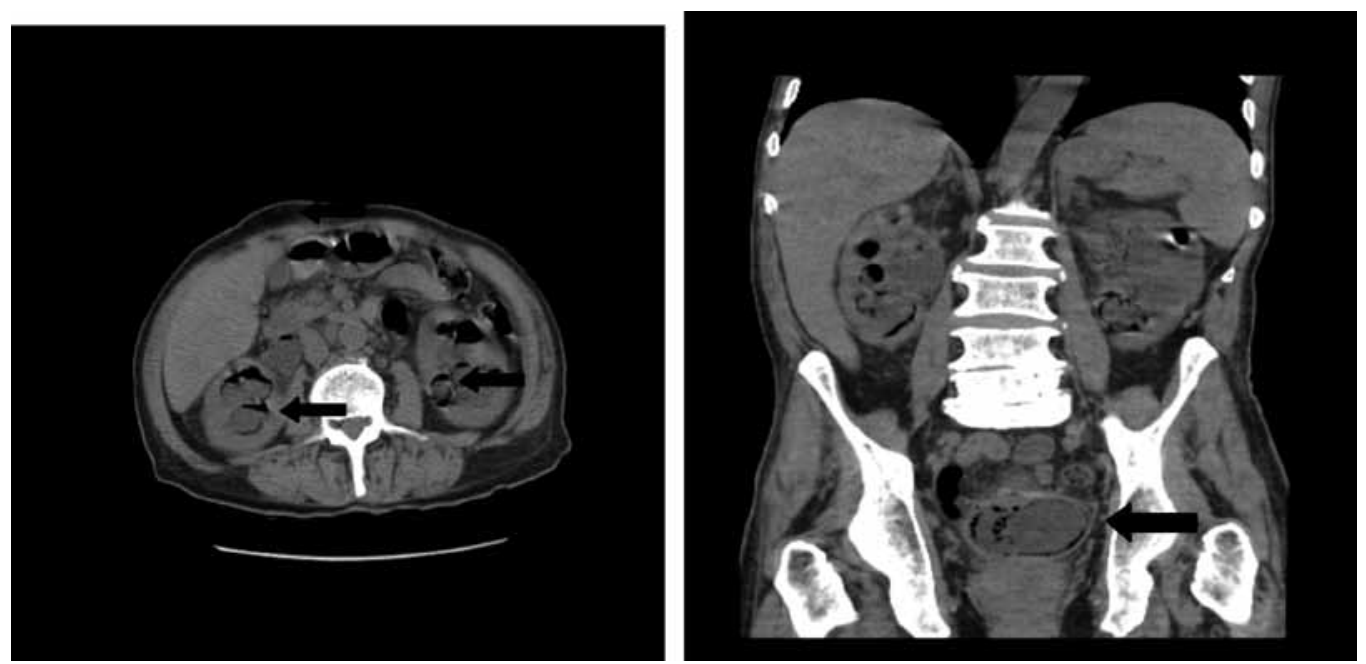

Figuras 3 y 4. TC abdomino-pélvico con presencia de gas en cálices de ambos riñones y vejiga urinaria.

\section{COMENTARIOS}

La cistitis enfisematosa (CE) es una entidad de etiología infecciosa y poco frecuente, que se caracteriza por la existencia de gas en la luz y paredes de la vejiga. Suele presentarse con más frecuencia en mujeres de 55-60 años con enfermedades de base, como infecciones recurrentes del tracto urinario, divertículos vesicales, vejiga neurógena, uropatía obstructiva, transplante renal, e inmunodepresión entre otras ${ }^{2}$. De todas ellas la DM, tanto el tipo 1 como el tipo 2, y sobre todo cuando existe un mal control, es la entidad con la que guarda una mayor relación, $62-87 \%^{3,4}$. Esto se debe a que en los pacientes diabéticos las concentraciones de glucosa en orina están elevadas lo que predispone a la formación de dióxido de carbono cuando es fermentada en presencia de gérmenes ${ }^{3}$. El microorganismo que con más frecuencia produce gas al infectar el aparato urinario es el Escherichia Coli (E.Coli) en un $63 \%$, aunque también están implicados otros como Klebsiella penumoniae fundamentalmente, Proteus mirabilis, Pseudomona aeruginosa Enterobacter aerogenes, Enterococos, Estafilococo aureus, Estreptococos, Nocardia, Clostridium perfringens y Candida albicans ${ }^{5}$. Aunque generalmente presenta un buen pronóstico puede evolucionar afectando al sistema colector y parénquima renal, lo que da lugar a una pielonefritis enfisematosa, complicación más excepcional que ensombrece el pronóstico con una mortalidad de hasta un $80 \%{ }^{6,7}$.

La clínica es inespecífica, y aunque se presenta habitualmente con síntomas leves de irritación vesi- cal, hematuria y dolor hipogástrico, puede complicarse con cuadros de peritonitis y shock séptico ${ }^{2,3}$. Un signo característico es la pneumaturia, presencia de gas en la orina, aunque no siempre se evidencia $^{2}$. Debido a la inespecificidad clínica las imágenes radiológicas resultan clave para obtener un diagnóstico de CE, ya que una radiografía simple del tracto urológico puede demostrar la presencia de gas en el interior de la vejiga, a nivel ureteral, perirrenal e intraparenquimatoso indicando en este caso compromiso renal ${ }^{4}$. La ecografía abdominal presenta una rentabilidad baja, y aunque puede revelar un incremento del grosor de las paredes vesicales su utilización es escasa. Es la TC la principal prueba diagnóstica, ya que permite apreciar la existencia de gas en la luz y paredes vesicales en la mayoría de los casos, así como a nivel intraparenquimatoso o periférico a las estructuras ${ }^{4}$. También es útil para establecer el diagnóstico diferencial con otros procesos que pueden justificar la presencia de aire en la vejiga como un traumatismo penetrante, procedimientos quirúrgicos, infecciones, una enfermedad inflamatoria intestinal, diverticulitis o una fístula enterovesical, y su relación con un posible carcinoma o complicación por radioterapia. ${ }^{4}$

El tratamiento de la CE requiere antibioterapia inicial e intensiva orientada hacia los gérmenes relacionados con obtención de un urocultivo previo y colocación de un drenaje vesical urinario con lo que se resuelve en la mayoría de los casos.

Cuando se complica con afectación del sistema renoureteral, se manifiesta como un cuadro de 
pielonefritis severa, presentando fiebre, dolor lumbar y malestar general, acompañado de vómitos y en ocasiones una masa abdominal palpable. La bioquímica muestra glucemia y urea elevadas, así como leucocitosis en el hemograma. La orina suele revelar piuria con crecimiento en el cultivo urinario. En estos casos el diagnóstico debe sospecharse en todo paciente diabético con cuadro de pielonefritis que no evolucione correctamente transcurridas 72-96 horas de tratamiento, y apoyado por la visualización de gas dentro del riñón o del sistema colector en una radiografía de tracto urológico 5 . No obstante la TC, confirmará el diagnóstico ya que permite localizar mejor el lugar anatómico que ocupa el gas y determinar así el pronóstico ${ }^{4-6}$.

Este caso revela dos de las complicaciones potencialmente graves del paciente diabético con mal control si no son tratadas a tiempo. Una CAD y una $C E$, mucho más inusual, que sin un tratamiento adecuado de forma urgente hubieran tenido consecuencias fatales. En conclusión, la CE es una complicación inusual que suele aparecer como un hallazgo radiológico en el contexto de una infección urinaria sobre todo en pacientes diabéticos con un inadecuado control. Por tanto es importante su prevención, por parte del médico de atención primaria, mediante medidas higiénico-dietéticas y el seguimiento riguroso de los parámetros glucémicos. Asimismo resulta fundamental su sospecha y diagnóstico tempranos para la instauración precoz de antibióticos, evitando así complicaciones severas por afectación renoureteral. Actualmente aunque la mortalidad ha disminuido, se sitúa sobre el $20 \%{ }^{4}$. En estos casos el tratamiento requiere la combinación de antibióticos y cirugía ${ }^{8}$.

\section{BIBLIOGRAFÍA}

1. Goday, A. Epidemiología de la diabetes y sus complicaciones no coronarias.. Rev Esp Cardiol. 2002; 55:657-70.

2. Galiano Baena JF, Caballero Romeu JP, Galán Llopis JA, Leivar Tamayo A, Lobato Encinas JJ. Cistitis enfisematosa. Caso clínico y revisión de literatura. Actas Urol Esp. 2008; 32:948-50.

3. Grupper M, Kravtsov A, Potasman I. Emphysematous Cystitis: Illustrative Case Report and Review of the Literature. Medicine 2007; 86: 47-53.

4. Young YR, Sheu BF, Lee CC, Chang SS, Li PL, Wu YS. Images in emergency medicine. Emphysematous cystitis. Ann Emerg Med 2008; 51:230-61.

5. Blanco Díez A, Barbagelata López A, Fernández Rosado E, Casas Muíño R, Chantada Abal V, González Martín M. Pielonefritis enfisematosa: presentación de un caso y revisión de la literatura. Actas Urol Esp. 2003; 27:721-25.

6. Benítez Morillo MF, Tejada Ruiz FJ, Casares Vivas M. Inusual combinación de infecciones urológicas productoras de gas en paciente diabética. Semergen. 2007; 33:276-7.

7. Mokkabberi R, Ravakhah K. Emphysematous urinary tract infections: Diagnosis, treatment and survival. Am J Med Sci 2007; 333: 111- 6 .

8. Ubee SS, McGlynn L,Fordham M. Emphysematous pyelonephritis.BJU Int. 2011;107: 1474-8. 